\title{
Plant Breeding \\ and Biotechnology
}

Academic Journal of the Korean Society of Breeding Science

\section{Editorial}

The Korean Society of Breeding Science was established on November 8, 1969. The Society has been sharing the knowledge on theoretical advances and their application for developing crop varieties by publishing 44 volumes on Genetics and Breeding Science in both Korean and English. Last year, the board members decided to create a separate journal in English.

The Korean Society of Breeding Science launched a new journal entitled "Plant Breeding and Biotechnology, PBB" (Homepage, http://www.plantbreedbio.org/) on March 31, 2013. The journal will accept research articles, reviews, and short communications written in English.

Plant Breeding and Biotechnology publishes original and peer-reviewed research and review articles in all areas of basic and practical researches in plant breeding and biotechnology, including breeding methodologies, genetics, and genomics of economically important crop species. Our goal is to provide readers with the cutting-edge information of genetic, genomic, and molecular techniques. Since the journal embraces all different aspects of plant improvement, readers from both academia and industry will benefit from what we will offer.

Plant Breeding and Biotechnology is aiming to become a world class journal for knowledge transfer and sharing through delivering advanced quality researches. PBB would very much appreciate your participation, so that PBB could grow and share the best of knowledge with the community. 